\title{
Chiari-related scoliosis: a single-center experience with long-term radiographic follow-up and relationship to deformity correction
}

\author{
*Vijay M. Ravindra, MD, MSPH, ${ }^{1}$ Kaine Onwuzulike, MD, PhD, ${ }^{2}$ Robert S. Heller, MD, ${ }^{3}$ \\ Robert Quigley, MD, ${ }^{4}$ John Smith, MD, ${ }^{4}$ Andrew T. Dailey, MD, ${ }^{1}$ and Douglas L. Brockmeyer, MD ${ }^{1}$

\begin{abstract}
${ }^{1}$ Department of Neurosurgery, University of Utah, Primary Children's Hospital; ${ }^{4}$ Department of Orthopedic Surgery, Primary Children's Hospital, Salt Lake City, Utah; ${ }^{2}$ Department of Neurosurgery, Cleveland Clinic, Cleveland, Ohio; and ${ }^{3}$ Department of Neurosurgery, Tufts Medical Center, Boston, Massachusetts
\end{abstract}

\begin{abstract}
OBJECTIVE Previous reports have addressed the short-term response of patients with Chiari-related scoliosis (CRS) to suboccipital decompression and duraplasty (SODD); however, the long-term behavior of the curve has not been well defined. The authors undertook a longitudinal study of a cohort of patients who underwent SODD for CRS to determine whether there are factors related to Chiari malformation (CM) that predict long-term scoliotic curve behavior and need for deformity correction.

METHODS The authors retrospectively reviewed cases in which patients underwent SODD for CRS during a 14-year period at a single center. Clinical (age, sex, and associated disorders/syndromes) and radiographic (CM type, tonsillar descent, pBC2 line, clival-axial angle [CXA], syrinx length and level, and initial Cobb angle) information was evaluated to identify associations with the primary outcome: delayed thoracolumbar fusion for progressive scoliosis.
\end{abstract}

RESULTS Twenty-eight patients were identified, but 4 were lost to follow-up and 1 underwent fusion within a year. Among the remaining 23 patients, 11 required fusion surgery at an average of $88.3 \pm 15.4$ months after SODD, including $7(30 \%)$ who needed fusion more than 5 years after SODD. On univariate analysis, a lower CXA $\left(131.5^{\circ} \pm 4.8^{\circ}\right.$ vs $146.5^{\circ}$ $\left.\pm 4.6^{\circ}, p=0.034\right), p B C 2>9 \mathrm{~mm}(64 \%$ vs $25 \%, p=0.06)$, and higher initial Cobb angle $\left(35.1^{\circ} \pm 3.6^{\circ}\right.$ vs $22.8^{\circ} \pm 4.0^{\circ}, p$ $=0.035$ ) were associated with the need for thoracolumbar fusion. Multivariable modeling revealed that lower CXA was independently associated with a need for delayed thoracolumbar fusion (OR 1.12, $p=0.0128)$.

CONCLUSIONS This investigation demonstrates the long-term outcome and natural history of CRS after SODD. The durability of the effect of SODD on CRS and curve behavior is poor, with late curve progression occurring in 30\% of patients. Factors associated with CRS progression include an initial $\mathrm{pBC} 2>9 \mathrm{~mm}$, lower $\mathrm{CXA}$, and higher Cobb angle. Lower CXA was an independent predictor of delayed thoracolumbar fusion. Further study is necessary on a larger cohort of patients to fully elucidate this relationship.

https://thejns.org/doi/abs/10.3171/2017.8.PEDS17318

KEY WORDS Chiari decompression; scoliosis; deformity correction; suboccipital decompression and duraplasty; syrinx; syringopleural shunt; thoracolumbar fusion; clival-axial angle; Cobb angle; long-term follow-up; spine

$\mathrm{C}$ HIARI malformation Type I (CM-I), a developmental abnormality of the hindbrain, is frequently associated with syringomyelia and scoliosis. ${ }^{13,31}$ The prevalence of scoliosis among patients with CM-I ranges from $13 \%$ to $36 \%$. ${ }^{13,5,29,31,33}$ In CM-I patients with a syrinx, the prevalence rises to $53 \%-85 \% .8,15,17,30$ Nearly $50 \%$ of patients with Chiari-related scoliosis (CRS) may require spinal fusion despite having undergone neurosurgical treatment. $8,9,25,31,34$ Patients with CRS may manifest with "atypical" findings, such as neurological deficit, a left apical curve, kyphotic deformity associated with the curve, or early onset. ${ }^{16}$ Known risk factors for curve progression and early spinal fusion include older age at presentation, level of spinal deformity, less syrinx resolution, and greater degree of initial scoliosis. ${ }^{2,3,16,24,27}$

Previous reports have addressed the short-term re-

ABBREVIATIONS CCJ = craniocervical junction; $\mathrm{CM}=$ Chiari malformation; $\mathrm{CM}-\mathrm{I}=\mathrm{CM}$ Type I; $\mathrm{CRS}=$ Chiari-related scoliosis; $\mathrm{CXA}=$ clival-axial angle; $\mathrm{SODD}=$ suboccipital decompression and duraplasty.

SUBMITTED June 9, 2017. ACCEPTED August 10, 2017.

INCLUDE WHEN CITING Published online November 24, 2017; DOI: 10.3171/2017.8.PEDS17318.

* Drs. Ravindra and Onwuzulike contributed equally to this work. 
sponse of CRS to suboccipital decompression and duraplasty (SODD). ${ }^{3,5,6,8,18,33,35}$ The aim of the current study was to investigate the long-term behavior of CRS in a cohort of patients who underwent SODD in order to determine whether there are clinical and radiographic factors that are predictive of need for late thoracolumbar fusion.

\section{Methods}

\section{Patient Population}

A single-center retrospective review of all cases involving patients with CRS treated from October 1, 1996, to June 30, 2009, was undertaken at Primary Children's Hospital/University of Utah. Institutional review board approval with waiver of consent was obtained. Standing scoliosis radiographs were obtained to provide a baseline Cobb angle for each patient. Specific inclusion criteria were diagnosis of CM-I (tonsillar herniation $>5 \mathrm{~mm}$ ) or CM-1.5 (tonsillar herniation $>5 \mathrm{~mm}$ and evidence of caudal descent of the brainstem), ${ }^{32}$ age $<18$ years at the time of diagnosis, history of surgically managed CM, and the presence of CRS (coronal angle of primary curve $>10^{\circ}$ ). Exclusion criteria were other CM types (CM-II, CM-III, or CM-IV), segmentation and formation anomalies of the vertebral column, and lack of long-term follow-up data.

\section{Data Collection}

Radiographic information was collected by 2 physicians-a pediatric neurosurgery fellow (craniocervical parameters) and a pediatric orthopedic fellow (thoracolumbar measurements) - and verified by the senior author (D.L.B.). The radiographic data included initial Cobb angles of the thoracolumbar curve, the $\mathrm{pBC} 2$ (a line perpendicular to the line between the basion and the posteroinferior aspect of the C-2 body on a sagittal MR image),${ }^{12}$ the clival-axial angle (CXA; measured as the angle subtended by a line drawn along the dorsal surface of the clivus and a second line drawn along the dorsal surface of the odontoid process on a sagittal CT reconstruction or sagittal MR image), presence of syrinx (both holocord and number of levels affected), and directionality of the curve. Clinical characteristics included age at initial SODD operation, length of follow-up, and the presence of syndromic or chromosomal abnormalities.

\section{Surgical Interventions}

Surgical interventions included SODD and scoliotic deformity correction. The decision to offer thoracolumbar deformity correction with posterior spinal fusion was based on evaluation by a senior pediatric orthopedic surgeon with a practice primarily composed of deformity correction. The criteria were those accepted in the literature, including progressive deformity, sitting balance, worsening pulmonary function, and increased symptoms from curvature (painful deformity and difficulty caring for the child). Indications for surgical correction included scoliosis that exceeded $45^{\circ}-50^{\circ}$ in children 10 years of age or older or significant deterioration in the child's functionality. ${ }^{14,19,21}$ Given the retrospective nature of the current study and primary outcome of requiring deformity cor- rection, surgical techniques and instrumentation type for correction were not analyzed.

\section{Statistical Analysis}

The data were descriptively reported as means with standard deviations for continuous data and as counts with percentages for categorical data. We analyzed demographic, clinical, and radiographic variables related to CM to elucidate risk factors for progressive scoliosis requiring deformity correction with posterior spinal fusion. An independent t-test was performed on all continuous variables to detect differences between groups. Continuous measurements were converted to ordinal variables (CXA greater than or less than $130^{\circ}$ and $\mathrm{pBC} 2$ greater than or less than $9 \mathrm{~mm}$ ) to analyze and interpret the data in a more clinically relevant manner.

Univariate analysis was performed to identify unadjusted risk factors for fusion using the chi-square test for categorical variables and independent t-test for continuous variables. Subsequently, multivariate logistic regression was performed including all clinically relevant variables and those with a value of $\mathrm{p}<0.20$ on univariate analysis. Statistical significance was set at $\mathrm{p}<0.05$. A Kaplan-Meier survival curve was generated to compare a CXA cutoff and time to fusion using the log-rank test.

\section{Results \\ Patient Cohorts}

A total of 28 patients were identified with CM-related scoliosis, of whom 4 were lost to follow-up. Of the remaining 24 patients, 1 patient had fusion surgery within a year of the SODD. Thus, 23 cases were available for long-term analysis: 12 patients did not undergo spinal fusion, and 11 patients required fusion surgery at an average of $88.3 \pm 15.4$ months (range 8-202 months) after SODD surgery (Table 1). Seven patients $(30 \%)$ required spinal fusion more than 5 years after SODD. Fifteen patients (65\%) had CM-1.5: 7 in the fusion group and 8 in the no-fusion group $(\mathrm{p}=0.88)$. The patients' mean age at initial SODD surgery was $97.3 \pm 55.3$ months (91.6 months in the fusion group vs 102.5 months in the nofusion group, $\mathrm{p}=0.65$ ). The mean duration of follow-up was $63.2 \pm 55.6$ months. The length of follow-up did differ between the 2 groups (mean $88.3 \pm 15.4$ months in the fusion group vs $40.3 \pm 14.7$ months in the no-fusion group, $\mathrm{p}=0.035$ ).

\section{Univariate Analysis}

We evaluated clinical and radiological factors with univariate analysis to determine whether they were associated with a need for late fusion (Table 1). Female sex was not significantly associated with delayed thoracolumbar fusion $(\mathrm{p}=0.21)$. Tonsillar descent $(\mathrm{p}=0.66)$, mean $\mathrm{pBC} 2(\mathrm{p}=$ $0.11)$, number of syrinx levels ( $\mathrm{p}=0.43)$, holocord syrinx ( $\mathrm{p}$ $=0.53)$, and atypical curve $(\mathrm{p}=0.89)$ were not associated with progression. $\mathrm{A} \mathrm{pBC} 2>9 \mathrm{~mm}(\mathrm{p}=0.06)$ and a greater initial Cobb angle $(\mathrm{p}=0.035)$ were associated with CRS progression. CXA was also associated with CRS progression (mean $139^{\circ} \pm 3.6^{\circ} ; 131.5^{\circ} \pm 4.8^{\circ}$ in the fusion group vs $146.5^{\circ} \pm 4.6^{\circ}$ in the no-fusion group, $\left.p=0.034\right)$. Seventeen 
TABLE 1. Univariate analysis comparing patients who needed delayed thoracolumbar fusion and those who did not

\begin{tabular}{lcccc}
\hline \multicolumn{1}{c}{ Variable } & Total Cohort & Delayed TL Fusion (11 pts) & No Delayed TL Fusion (12 pts) & $p$ Value \\
\hline Mos of follow-up & $63.2 \pm 55.6$ & $88.3 \pm 15.4$ & $40.3 \pm 14.7$ & 0.035 \\
\hline Female sex & $9 / 23(39 \%)$ & $6 / 11(55 \%)$ & $3 / 12(25 \%)$ & 0.214 \\
\hline Age at SODD (mos) & $97.3 \pm 55.3$ & $91.6 \pm 17.0$ & $102.5 \pm 16.2$ & 0.65 \\
\hline No. of pts w/ CM 1.5 (\%) & $15 / 23(65)$ & $7 / 11(64)$ & $8 / 12(67)$ & 0.88 \\
\hline Tonsillar descent (mm) & $9.02 \pm 5.77$ & $8.5 \pm 1.8$ & $9.5 \pm 1.7$ & 0.66 \\
\hline pBC2 (mm) & $8.69 \pm 2.48$ & $9.56 \pm 0.71$ & $7.88 \pm 0.69$ & 0.11 \\
\hline No. of pts w/ pBC2 $>9$ mm (\%) & $10 / 23(43)$ & $7 / 11(64)$ & $3 / 12(25)$ & 0.06 \\
\hline CXA & $139 \pm 3.60$ & $131.5 \pm 4.8$ & $146.5 \pm 4.6$ & 0.034 \\
\hline No. of pts w/ CXA >130 $(\%)$ & $17 / 23(74)$ & $7 / 11(64)$ & $10 / 12(83)$ & 0.28 \\
\hline No. of syrinx levels & $12.6 \pm 6.3$ & $11.5 \pm 1.9$ & $13.6 \pm 1.8$ & 0.43 \\
\hline No. of pts w/ holocord syrinx (\%) & $5 / 23(22)$ & $3 / 11(27)$ & $2 / 12(17)$ & 0.53 \\
\hline Initial Cobb angle $\left({ }^{\circ}\right)$ & $29.6 \pm 13.3$ & $35.1 \pm 3.6$ & $22.8 \pm 4.0$ & 0.035 \\
\hline No. of pts w/ atypical curve (\%) & $13 / 23(57)$ & $7 / 11(64)$ & $6 / 12(50)$ & 0.89 \\
\hline No. of pts w/ levoscoliosis (\%) & $8 / 23(35)$ & $5 / 11(45)$ & $3 / 12(25)$ & 0.83 \\
\hline Time to fusion procedure (mos) & - & $88.3 \pm 15.4$ & - & - \\
\hline No. of pts w/ chromosomal abnormality $(\%)$ & $7 / 23(30)$ & $5 / 11(45)$ & $2 / 12(17)$ & 0.13 \\
\hline
\end{tabular}

pts = patients; $\mathrm{TL}=$ thoracolumbar.

Values are mean \pm SD unless otherwise indicated. Boldface type indicates statistical significance $(p<0.05)$.

patients had a CXA $>130^{\circ}$ (10 in the fusion group vs 7 in the no-fusion group, $\mathrm{p}=0.28$ ). The mean time to the fusion procedure was $88.3 \pm 15.4$ months (range 10-202 months); patients with a CXA $>130^{\circ}$ had longer time to fusion than those with a CXA $<130^{\circ}(\mathrm{p}=0.46)$.

\section{Multivariate Analysis}

Multivariate analysis with chi-square analysis using clinically relevant and statistically significant variables from the univariate analysis (Table 2) demonstrated that lower CXA was independently associated with delayed thoracolumbar fusion (OR 1.12, $\mathrm{p}=0.0128$ ).

\section{Discussion}

This investigation demonstrates the long-term outcome and natural history of CRS after SODD. We found that delayed late curve progression occurred in $30 \%$ of patients at more than 5 years after SODD. Factors associated with CRS progression include an initial $\mathrm{pBC} 2>9 \mathrm{~mm}$, lower CXA, and greater Cobb angle. Lower CXA was an independent predictor of delayed thoracolumbar fusion. This is the first report of CM-related measurements as factors associated with delayed deformity correction for thoracolumbar scoliosis.

Dauser et al. ${ }^{7}$ was the first to describe the association between CM and scoliosis. Previous reports on CRS and the need for deformity correction have focused on characteristics of the thoracolumbar curvature. Although the Cobb angle of the scoliotic curve is of obvious importance, we have shown that CM-related measurements may influence the development of delayed deformity requiring correction and, at the very least, warrant further investigation. For patients with CM-I, previous reports have suggested that patients with scoliotic curvature between $30^{\circ}$ and $40^{\circ}$ go on to require spinal fusion following suboccipital decompression. $3,5,6,8,18,33,35$

With regard to CM-related measurements, in a series of 101 patients who underwent SODD, 19 of whom underwent occipital-cervical fusion, Bollo et al. ${ }^{4}$ demonstrated that patients with basilar invagination, CM-1.5, and CXA $<125^{\circ}$ were at increased risk of requiring occipitocervical fusion; this study was an initial description of the importance of the CXA in evaluating alignment in patients with $\mathrm{CM}$. In the present investigation, an association with lower CXA and the need for delayed thoracolumbar fusion was found. Further attention to the skull base-spine relationship in patients with CRS could be important in determining the natural history of curve progression and would enable counseling of families on the risk of the need for deformity correction in the future.

Multiple thresholds for curve progression have been previously reported. Tubbs et al. ${ }^{33}$ reviewed 16 cases and found that decompression alone did not resolve curvature $>40^{\circ}$. In a similar fashion, Ghanem et al..$^{11}$ found that all patients who presented with a curve $\geq 40^{\circ}$ required fusion. Zhu et al. ${ }^{35}$ found a $44.5^{\circ}$ threshold that was specific for curve progression. In addition to measuring the Cobb angle, we focused on the need for deformity correction and spinal fusion as the primary outcome. Given the wide ar-

TABLE 2. Multivariate analysis evaluating factors associated with the need for delayed thoracolumbar fusion

\begin{tabular}{lllc}
\hline \multicolumn{1}{c}{ Variable } & $\chi^{2}$ & p Value & OR 95\% Cl \\
\hline CXA & 6.2 & 0.0128 & $1.12(0.99-1.25)$ \\
\hline Follow-up: duration in mos & 0.90 & 0.34 & $0.98(0.94-1.02)$ \\
\hline Initial Cobb angle & 3.46 & 0.06 & $0.84(0.66-1.06)$ \\
\hline
\end{tabular}


ray of curvature progression reported in the literature, we believe the outcome of correction was more appropriate in ascertaining risk factors. In the current investigation, we found a higher initial Cobb angle ( $35.1^{\circ}$ vs $\left.22.8^{\circ}, \mathrm{p}=0.035\right)$ in the fusion group on univariate modeling. Although this factor did not retain its significance on multivariate modeling ( $p=0.06)$, we believe that initial Cobb angle is important for the progression of thoracolumbar scoliosis requiring surgical correction; the small sample size of the cohort may have limited the ability of the analysis to detect its association.

Mackel et al. ${ }^{20}$ found that fusion after posterior fossa decompression surgery was a reflection of curve severity and that patients with curves $>35^{\circ}$ and patients 10 years of age or older were at greater risk for requiring fusion/correction surgery; their study only included patients with CM-I and excluded CM-1.5 patients. Age as a risk factor has previously been reported. Sengupta et al., ${ }^{27}$ Brockmeyer et al., ${ }^{5}$ and Flynn et al. ${ }^{10}$ reported that early presentation (age $<10$ years) was associated with $71 \%, 91 \%$, and $70 \%$ avoidance rates of fusion, respectively. Similar to the results of Navarro et al., ${ }^{23}$ however, the results of our present investigation showed no statistically significant association with age at decompression (overall mean $97.3 \pm 55.3$ months $[\sim 8$ years]; 91.6 months in the fusion group vs 102.5 months in the no-fusion group, $\mathrm{p}=0.65$ ).

Although there have been previous studies on Chiari decompression and the effect on the scoliotic curve, to our knowledge this is the first report of long-term follow-up of CRS with CM-specific risk factors (i.e., $\mathrm{pBC} 2$ and CXA) as they relate to global spinal alignment. On multivariate modeling, we found the lower CXA to be a predictor of a need for delayed deformity correction (OR 1.12, $\mathrm{p}=$ 0.0128 ). The scoliosis severity (Cobb angle) did not uniformly improve in patients who underwent SODD and did not undergo delayed thoracolumbar fusion: of the 12 patients who did not go on to require fusion, 3 had worsened Cobb angles after SODD, 4 had improved Cobb angles, and 5 had no imaging studies available for evaluation. This is in contrast to the results of Muhonen et al., ${ }^{22}$ which demonstrated that scoliosis after decompression resolved in all children under age 10 years in their series even though this included curves that exceeded $40^{\circ}$.

We found no association between the presence of syrinx or the number of levels affected by it and the severity of CM (CM-I vs CM-1.5); however, given the small sample size, we do not recommend discounting these factors as potential contributors to scoliosis curve progression over time. The strength of the current investigation lies in the length of follow-up for both groups (mean 5 years), specifically in the delayed thoracolumbar fusion cohort; this highlights the importance of long-term clinical follow-up and the need for radiographic surveillance over time, especially in patients with lower CXA. Global spinal alignment, specifically how cervical alignment is impacted by thoracolumbar regional alignment, has recently become a topic of interest in the adult deformity literature. ${ }^{28}$ The pediatric craniocervical junction $(\mathrm{CCJ})$ is a complex network of bony elements (occiput, atlas [C-1], axis [C-2]), ligamentous structures, and soft tissue and muscle development. ${ }^{26}$ We postulate that the regional alignment of the
$\mathrm{CCJ}$ is intimately involved with regional alignment of the thoracolumbar spine. Thus, abnormalities of the CCJ may correlate with thoracolumbar curve progress, which may be a result of compensatory mechanisms to reestablish global alignment. We believe the findings of this study contribute to this notion and require further attention in the field of pediatric spinal deformity.

\section{Limitations}

There are limitations to this study, including its retrospective nature, the variable time intervals to follow-up, and the relatively small sample size. The limitations of small sample size are reflected in the statistical analysis, which may be underpowered to detect meaningful differences and limit the conclusions that can be drawn. For example, the between-groups difference in initial Cobb angle was significant on univariate analysis $(p=0.035)$ but not on multivariate modeling $(\mathrm{p}=0.06)$. Furthermore, although efforts were undertaken to verify the accuracy of all measurements, lack of standardization could introduce some element of measurement bias.

Given these findings, we believe that further study is needed on a larger cohort of prospectively collected patients for verification. The findings suggest, for the first time, that craniocervical parameters and initial Cobb angle are important factors in the natural history of CRS and mandate that close long-term follow-up is necessary in all patients with this disorder. With this information, we suggest that patients with $\mathrm{CM}$ and scoliosis have extended follow-up out to 5 years or even longer and should have long-cassette standing scoliosis radiographs to monitor progression. In addition, more attention should be paid to the preoperative measures, specifically CXA and pBC2.

\section{Conclusions}

The long-term behavior of scoliotic curves is relatively poor in patients who have undergone SODD for treatment of CRS, with fusion surgery subsequently required in nearly half of patients and late curve progression occurring in $30 \%$ of patients. Factors associated with CRS progression include an initial $\mathrm{pBC} 2>9 \mathrm{~mm}$, lower CXA, and higher Cobb angle. Lower CXA was an independent predictor of a need for delayed thoracolumbar fusion in this study. These parameters warrant attention when assessing children with CRS, although further study on a larger cohort of patients is needed to fully elucidate these findings.

\section{Acknowledgments}

We thank Kristin Kraus, MSc, for editorial assistance with this paper.

\section{References}

1. Attenello FJ, McGirt MJ, Atiba A, Gathinji M, Datoo G, Weingart J, et al: Suboccipital decompression for Chiari malformation-associated scoliosis: risk factors and time course of deformity progression. J Neurosurg Pediatr 1:456-460, 2008

2. Attenello FJ, McGirt MJ, Garcés-Ambrossi GL, Chaichana KL, Carson B, Jallo GI: Suboccipital decompression for Chiari I malformation: outcome comparison of duraplasty 
with expanded polytetrafluoroethylene dural substitute versus pericranial autograft. Childs Nerv Syst 25:183-190, 2009

3. Bhangoo R, Sgouros S: Scoliosis in children with Chiari Irelated syringomyelia. Childs Nerv Syst 22:1154-1157, 2006

4. Bollo RJ, Riva-Cambrin J, Brockmeyer MM, Brockmeyer DL: Complex Chiari malformations in children: an analysis of preoperative risk factors for occipitocervical fusion. J Neurosurg Pediatr 10:134-141, 2012

5. Brockmeyer D, Gollogly S, Smith JT: Scoliosis associated with Chiari 1 malformations: the effect of suboccipital decompression on scoliosis curve progression: a preliminary study. Spine (Phila Pa 1976) 28:2505-2509, 2003

6. Brockmeyer DL: Editorial. Chiari malformation Type I and scoliosis: the complexity of curves. J Neurosurg Pediatr 7:22-24, 2011

7. Dauser RC, DiPietro MA, Venes JL: Symptomatic Chiari I malformation in childhood: a report of 7 cases. Pediatr Neurosci 14:184-190, 1988

8. Eule JM, Erickson MA, O'Brien MF, Handler M: Chiari I malformation associated with syringomyelia and scoliosis: a twenty-year review of surgical and nonsurgical treatment in a pediatric population. Spine (Phila Pa 1976) 27:1451-1455, 2002

9. Farley FA, Puryear A, Hall JM, Muraszko K: Curve progression in scoliosis associated with Chiari I malformation following suboccipital decompression. J Spinal Disord Tech 15:410-414, 2002

10. Flynn JM, Sodha S, Lou JE, Adams SB Jr, Whitfield B, Ecker ML, et al: Predictors of progression of scoliosis after decompression of an Arnold Chiari I malformation. Spine (Phila Pa 1976) 29:286-292, 2004

11. Ghanem IB, Londono C, Delalande O, Dubousset JF: Chiari I malformation associated with syringomyelia and scoliosis. Spine (Phila Pa 1976) 22:1313-1318, 1997

12. Grabb PA, Mapstone TB, Oakes WJ: Ventral brain stem compression in pediatric and young adult patients with Chiari I malformations. Neurosurgery 44:520-528, 1999

13. Hankinson T, Tubbs RS, Wellons JC: Duraplasty or not? An evidence-based review of the pediatric Chiari I malformation. Childs Nerv Syst 27:35-40, 2011

14. Herring JA: Disorders of the brain, in Herring JA (ed): Tachjian's Pediatric Orthopaedics. Philadelphia: Saunders, 2002, pp 1121-1248

15. Hida K, Iwasaki Y, Koyanagi I, Abe H: Pediatric syringomyelia with Chiari malformation: its clinical characteristics and surgical outcomes. Surg Neurol 51:383-391, 1999

16. Hwang SW, Samdani AF, Jea A, Raval A, Gaughan JP, Betz RR, et al: Outcomes of Chiari I-associated scoliosis after intervention: a meta-analysis of the pediatric literature. Childs Nerv Syst 28:1213-1219, 2012

17. Isu T, Iwasaki Y, Akino M, Abe H: Hydrosyringomyelia associated with a Chiari I malformation in children and adolescents. Neurosurgery 26:591-597, 1990

18. Lee S, Wang KC, Cheon JE, Phi JH, Lee JY, Cho BK, et al: Surgical outcome of Chiari I malformation in children: clinico-radiological factors and technical aspects. Childs Nerv Syst 30:613-623, 2014

19. Lonstein JE, Akbarnia A: Operative treatment of spinal deformities in patients with cerebral palsy or mental retardation. An analysis of one hundred and seven cases. J Bone Joint Surg Am 65:43-55, 1983

20. Mackel CE, Cahill PJ, Roguski M, Samdani AF, Sugrue PA, Kawakami N, et al: Factors associated with spinal fusion after posterior fossa decompression in pediatric patients with Chiari I malformation and scoliosis. J Neurosurg Pediatr 25:737-743, 2016

21. McCarthy RE: Management of neuromuscular scoliosis. Orthop Clin North Am 30:435-449, viii, 1999

22. Muhonen MG, Menezes AH, Sawin PD, Weinstein SL: Sco- liosis in pediatric Chiari malformations without myelodysplasia. J Neurosurg 77:69-77, 1992

23. Navarro R, Olavarria G, Seshadri R, Gonzales-Portillo G, McLone DG, Tomita T: Surgical results of posterior fossa decompression for patients with Chiari I malformation. Childs Nerv Syst 20:349-356, 2004

24. Ozerdemoglu RA, Transfeldt EE, Denis F: Value of treating primary causes of syrinx in scoliosis associated with syringomyelia. Spine (Phila Pa 1976) 28:806-814, 2003

25. Phillips LH II, Blanco JS, Sussman MD: Direct spinal stimulation for intraoperative monitoring during scoliosis surgery. Muscle Nerve 18:319-325, 1995

26. Phuntsok R, Mazur MD, Ellis BJ, Ravindra VM, Brockmeyer DL: Development and initial evaluation of a finite element model of the pediatric craniocervical junction. J Neurosurg Pediatr 17:497-503, 2016

27. Sengupta DK, Dorgan J, Findlay GF: Can hindbrain decompression for syringomyelia lead to regression of scoliosis? Eur Spine J 9:198-201, 2000

28. Smith JS, Shaffrey CI, Bess S, Shamji MF, Brodke D, Lenke LG, et al: Recent and emerging advances in spinal deformity. Neurosurgery 80:S70-S85, 2017

29. Strahle J, Muraszko KM, Kapurch J, Bapuraj JR, Garton HJ, Maher CO: Chiari malformation Type I and syrinx in children undergoing magnetic resonance imaging. J Neurosurg Pediatr 8:205-213, 2011

30. Strahle J, Smith BW, Martinez M, Bapuraj JR, Muraszko KM, Garton HJ, et al: The association between Chiari malformation Type I, spinal syrinx, and scoliosis. J Neurosurg Pediatr 15:607-611, 2015

31. Tubbs RS, Beckman J, Naftel RP, Chern JJ, Wellons JC III, Rozzelle CJ, et al: Institutional experience with 500 cases of surgically treated pediatric Chiari malformation Type I. J Neurosurg Pediatr 7:248-256, 2011

32. Tubbs RS, Iskandar BJ, Bartolucci AA, Oakes WJ: A critical analysis of the Chiari 1.5 malformation. J Neurosurg 101 (2 Suppl):179-183, 2004

33. Tubbs RS, McGirt MJ, Oakes WJ: Surgical experience in 130 pediatric patients with Chiari I malformations. J Neurosurg 99:291-296, 2003

34. Yeom JS, Lee CK, Park KW, Lee JH, Lee DH, Wang KC, et al: Scoliosis associated with syringomyelia: analysis of MRI and curve progression. Eur Spine J 16:1629-1635, 2007

35. Zhu Z, Wu T, Zhou S, Sun X, Yan H, Sha S, et al: Prediction of curve progression after posterior fossa decompression in pediatric patients with scoliosis secondary to Chiari malformation. Spine Deform 1:25-32, 2013

\section{Disclosures}

Dr. Dailey reports consultant relationships with Medtronic, K2M, and Zimmer-Biomet and receipt of support for non-study-related clinical or research effort from K2M.

\section{Author Contributions}

Conception and design: Brockmeyer, Onwuzulike. Acquisition of data: Ravindra. Analysis and interpretation of data: Ravindra, Heller. Drafting the article: Ravindra. Critically revising the article: Onwuzulike, Heller, Quigley, Smith, Dailey. Reviewed submitted version of manuscript: Brockmeyer, Onwuzulike, Heller, Quigley, Smith, Dailey. Approved the final version of the manuscript on behalf of all authors: Brockmeyer.

\section{Correspondence}

Douglas L. Brockmeyer, Department of Neurosurgery, Primary Children's Hospital, University of Utah, 100 N Mario Capecchi Dr., Salt Lake City, UT 84113. email: neuropub@hsc.utah.edu. 